\title{
Defining the role of neutrophil-to-lymphocyte ratio in COPD: a systematic literature review
}

This article was published in the following Dove Press journal: International Journal of COPD

Yuliana Pascual-González' Marta López-Sánchez' Jordi Dorca' Salud Santos ${ }^{1,2}$

'Department of Respiratory Medicine, Bellvitge University Hospital - IDIBELL, University of Barcelona, L'Hospitalet de Llobregat, Barcelona, Spain; ${ }^{2}$ Biomedical Research Networking Center Consortium - Respiratory Diseases (CIBERES), Barcelona, Spain
Correspondence: Salud Santos Department of Respiratory Medicine, Bellvitge University Hospital - IDIBELL, University of Barcelona, c/Feixa Llarga s/n CP 08907, L'Hospitalet de Llobregat, Barcelona, Spain

Tel +34932607685

Fax +34932607639

Email saludsantos@bellvitgehospital.cat

\begin{abstract}
COPD is characterized by a pulmonary and systemic inflammatory process. Several authors have reported the elevation of multiple inflammatory markers in patients with COPD; however, their use in routine clinical practice has limitations. The neutrophil-to-lymphocyte ratio (NLR) is a useful and cost-effective inflammatory marker derived from routine complete blood count. We performed a systematic literature review using the PRISMA statement. Twenty-two articles were included, recruiting 7,601 COPD patients and 784 healthy controls. Compared with controls, COPD patients had significantly higher NLR values. We found a significant correlation between the NLR and clinical/functional parameters ( $\mathrm{FEV}_{1}, \mathrm{mMRC}$, and BODE index) in COPD patients. Elevation of the NLR is associated with the diagnosis of acute exacerbation of COPD (pooled data propose a cut-off value of 3.34 with a median sensitivity, specificity, and area under the curve of $80 \%, 86 \%$, and 0.86 , respectively). Additionally, increased NLR is also associated with the diagnosis of a bacterial infection in exacerbated patients, with a cut-off value of 7.30, although with a low sensitivity and specificity. The NLR is an independent predictor of in-hospital and late mortality after exacerbation. In conclusion, the NLR could be a useful marker in COPD patients; however, further studies are needed to better identify the clinical value of the NLR.
\end{abstract}

Keywords: acute exacerbations of COPD, bacterial infection, mortality in COPD, inflammatory biomarkers, eosinophilia, GOLD stage

\section{Introduction}

COPD is a major public health problem worldwide and is characterized by poorly reversible airflow limitation and/or alveolar abnormalities. It is usually associated by persistent respiratory symptoms, disease progression, and, in some patients, multiple acute exacerbations. ${ }^{1}$ COPD accounted for $6 \%$ of all deaths globally in 2012 and is currently ranked as the fourth leading cause of death worldwide with a projection to increase in the coming decade., ${ }^{2,3}$ Chronic inflammation of the airways and the lung parenchyma is the classic paradigm for the pathogenesis of COPD and is associated with goblet cell proliferation, gland hyperplasia, fibrosis, collapse of small airways, and parenchymal destruction. ${ }^{4}$ However, there is increasing evidence that COPD also results in systemic inflammation and extra-pulmonary manifestations. ${ }^{5}$

Acute exacerbation of COPD (AECOPD) is related to more severe airway and systemic inflammation than in stable disease patients, and is associated with worse clinical symptoms, reduced lung function, increase hospitalization and intensive care unit admission rates, and more intensive treatments. ${ }^{6,7}$ The main causes of exacerbations in COPD are viral or bacterial infections, while $15 \%-20 \%$ are caused by other microorganisms or unspecified causes. ${ }^{8}$ 
There are limited data regarding inflammatory biomarkers in stable and exacerbated patients in standard clinical practice. However, recent studies have shown that the neutrophil-tolymphocyte ratio (NLR) is a reliable marker of systemic inflammation and a routinely performed test (complete blood counts), because of its rapidity and easy detection, availability, and cost-effectiveness. ${ }^{9,10}$ Based on the physiological response of circulating leukocytes to precipitating stress factors, with increased numbers of neutrophils and fewer lymphocytes, the ratio between these two subgroups has been evaluated in periods of inflammation in different diseases, such as lung cancer, colorectal cancer, end-stage renal disease, and acute coronary syndrome, among others. ${ }^{11-14}$

The aim of the present systematic review was to investigate 1) the role of the NLR in the severity of COPD according to clinical and functional outcomes (airflow obstruction $\left[\mathrm{FEV}_{1}\right]$, dyspnea [mMRC], and exercise capacity [BODE index]); 2) the relation between NLR and other inflammatory biomarkers; and 3) the ability of the NLR to detect or predict the diagnosis of exacerbation, bacterial infection, and mortality.

\section{Materials and methods \\ Design}

This systematic review was performed in accordance with the PRISMA statement. ${ }^{15}$

\section{Search strategy}

The search was carried out using the databases PubMed/ Medline, Google Scholar, Scielo, and Scopus, using a combination of the key words: "neutrophil-to-lymphocyte ratio", "NLR", "chronic obstructive pulmonary disease", "COPD”, "lung disease", "exacerbation", "prognosis", and "lung function". The search included articles published up to January 2018 and was limited to English language studies. The automatic search was complemented by a manual search to identify relevant articles. The search results were exported to the reference manager EndNote (Thompson Reuters), with a total of 482 records identified after duplicates were removed.

\section{Inclusion criteria and study eligibility}

The articles were screened by abstracts and full text. Disagreements were resolved by a senior author. Articles that contained the following information were included: 1) diagnosis of COPD according to the GOLD or the American Thoracic Society or the European Respiratory Society, or clearly defined similar criteria; 2) analysis of the associations between NLR and clinical features or outcomes of COPD patients; and 3) NLR cut-off value. The exclusion criteria were 1) review articles, editorial comments, letters, conference abstracts; 2) preclinical studies; or 3 ) full text unavailable and non-English article.

\section{Data extraction}

A standardized extraction form was used to collect data. The data extracted were: 1) authors, year of publication, study design, and sample size; 2) participant characteristics (age, gender); 3) NLR cut-off value and accuracy characteristics; 4) total NLR value in patient subgroups (healthy controls, stable COPD, exacerbated COPD); 5) total NLR value in different severity subgroups according to GOLD; 6) correlation coefficient between $\mathrm{NLR}_{\text {and }} \mathrm{FEV}_{1}$; 7) correlation coefficient between NLR and clinical parameters of COPD (6-minute walking distance, body mass index, airflow obstruction, and mMRC dyspnea scale); and 8) correlation coefficient between NLR and other inflammatory markers (C-reactive protein $[\mathrm{CRP}]$, erythrocyte sedimentation rate [ESR], and white blood cells).

\section{Quality assessment}

The quality of the included studies was analyzed using the Newcastle-Ottawa Quality Assessment Scale (NOS) for cohort, case-control, and cross-sectional studies. This scale is based on three characteristics: selection, comparability, and outcome or exposure (in case-control studies). ${ }^{16}$ In this "star system", a maximum of nine stars can be given for cohort and case-control studies, while cross-sectional studies can be given a maximum of ten stars. The thresholds for converting the NOS to Agency for Healthcare Research and Quality standards (good, fair, and poor) were: good quality -3 or 4 stars in selection domain, 1 or 2 stars in comparability domain, and 2 or 3 stars in outcome/exposure domain; fair quality - 2 stars in selection domain, 1 or 2 stars in comparability domain, and 2 or 3 stars in outcome/exposure domain; and poor quality - 0 or 1 star in selection domain, or 0 stars in comparability domain, or 0 or 1 stars in outcome/ exposure domain. ${ }^{17}$

\section{Statistical analysis}

The continuous variables were expressed as mean \pm SD. In articles in which the continuous variables were expressed as median and interquartile range, mean and SD were calculated according to Hozo et al. ${ }^{18}$ Accuracy data and the correlation between the NLR and clinical parameters or other inflammatory markers were expressed as Pearson's 
correlation coefficient or Spearman's Rho. The differences in NLR between groups were estimated using one-way ANOVA with Bonferroni as post hoc test or an unpaired $t$-test. Statistical analysis was performed using SPSS v22 (IBM SPSS Inc., Armonk, NY, USA). Statistical significance was considered with a value of $P<0.05$.

\section{Results}

\section{Selected studies}

Figure 1 shows the flow diagram of the studies. A total of 803 references were found through the literature search (795 automatic searches and eight manual searches). Initially, 321 were duplicates, and the remaining 483 were screened by title and abstract; of these, 459 were excluded and 25 were selected for full-text screening, of which 22 were eligible for inclusion, recruiting a total of 8,385 patients $(7,601$ COPD patients and 784 healthy controls) with a mean age of $65.65 \pm 6.20$ years, 5,812 (70\%) males, and 2,573 (30\%) females. Table 1 summarizes the characteristics of the articles and the population included. Articles in which the same group of COPD patients was evaluated in both periods of the disease (stable and exacerbated) were considered as providing independent data for statistical analysis. ${ }^{10,19-21}$

\section{Quality assessment}

The present systematic review included five cohort studies, six cross-sectional studies, and eleven case-control studies. Using the NOS form, 20 articles were identified as high quality (five cohort studies, five cross sectional studies, and ten case-control studies), and only two articles were identified as poor quality (one cross-sectional study and one casecontrol study) (Table 2).

\section{Neutrophil-to-lymphocyte ratio and COPD exacerbation}

The mean NLR values of healthy controls and stable and exacerbated COPD patients were extracted from $8,{ }^{10,21,23-28}$ $18,9,10,19-21,23-25$ and 17 articles, ${ }^{9,10,19-26,28,32,34-38}$ respectively. The pooled data showed that the mean NLR values of healthy controls, and stable and exacerbated COPD patients were $1.71 \pm 0.22,2.97 \pm 1.10$, and $7.76 \pm 3.79$, respectively (Table 3 ). The NLR in COPD patients with exacerbation was significantly

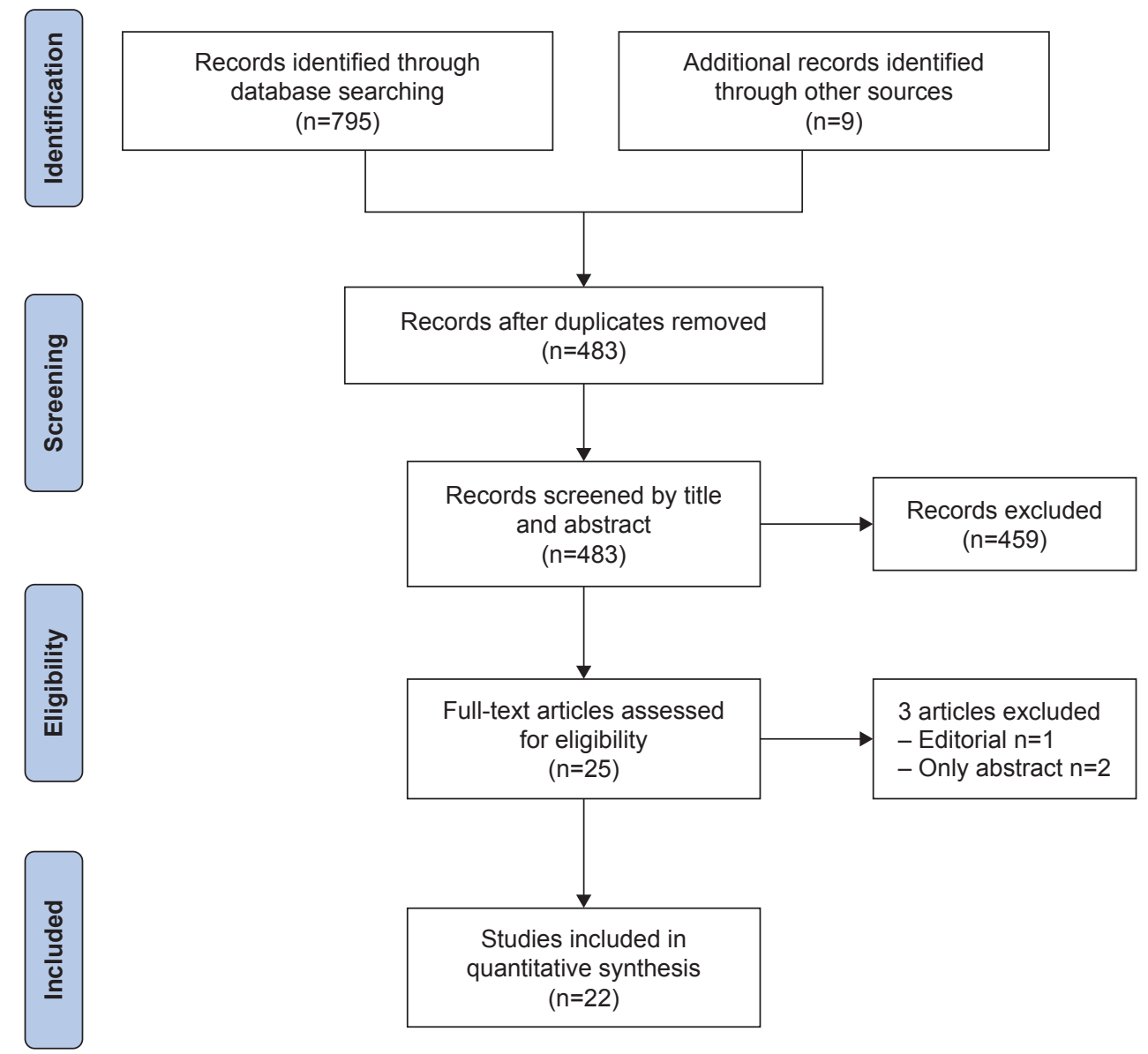

Figure I Flowchart of the systematic review. 
Table I Characteristics of included articles and population

\begin{tabular}{|c|c|c|c|c|c|c|c|c|c|}
\hline \multirow[t]{3}{*}{ Author, year } & \multirow{3}{*}{$\begin{array}{l}\text { Study } \\
\text { design }\end{array}$} & \multirow{3}{*}{$\begin{array}{l}\text { Age, } \\
\text { years (SD) }\end{array}$} & \multicolumn{2}{|c|}{ Gender } & \multicolumn{5}{|c|}{ Number of patients } \\
\hline & & & \multirow[t]{2}{*}{ Male } & \multirow[t]{2}{*}{ Female } & \multirow[t]{2}{*}{ Control } & \multicolumn{3}{|l|}{ COPD } & \multirow{2}{*}{$\begin{array}{l}\text { Total } \\
\text { patients }\end{array}$} \\
\hline & & & & & & Stable & Exacerbated & \begin{tabular}{|l|} 
Total \\
COPD
\end{tabular} & \\
\hline Günay et al, $2014^{22}$ & Retrospective & $65.76(7.62)$ & 216 & 103 & 50 & 178 & 91 & 269 & 319 \\
\hline Tanriverdi et al, 2015 $5^{36}$ & Prospective & $71.70(9.50)$ & 56 & 21 & - & - & 77 & 77 & 77 \\
\hline Sørensen et al, $2015^{29}$ & Prospective & $70.13(3.16)$ & 191 & 195 & - & 386 & - & 386 & 386 \\
\hline Taylan et al, $2015^{10}$ & Retrospective & $63.97(11.60)$ & 117 & 63 & 80 & 100 & 100 & 100 & 180 \\
\hline Saltürk et al, $2015^{19}$ & Retrospective & $67.75(6.05)$ & 523 & 124 & - & 647 & 647 & 647 & 647 \\
\hline Duman et al, $2015^{20}$ & Retrospective & $70.50(4.90)$ & 1,116 & 588 & - & $\mathrm{I}, 704$ & 1,704 & I,704 & I,704 \\
\hline Kurtipek et al, $2015^{9}$ & Prospective & 64.66 (9.79) & 94 & 0 & - & 48 & 46 & 94 & 94 \\
\hline Bilir et al, $2016^{23}$ & Retrospective & 54.90 (13.97) & 519 & 98 & 215 & 216 & 186 & 402 & 617 \\
\hline Furutate et al, $2016^{30}$ & Prospective & $71.20(7.46)$ & 137 & 4 & - & $14 \mid$ & 49 & $|4|$ & $|4|$ \\
\hline In et al, $2016^{24}$ & Retrospective & $65.67(9.17)$ & 112 & 31 & 40 & 56 & 47 & 103 & 143 \\
\hline Duyar, $2016^{31}$ & Retrospective & 67 (NS) & 39 & 0 & - & 39 & - & 39 & 39 \\
\hline van de Geijn et al, $2016^{32}$ & Retrospective & $67.55(2.45)$ & 22 & 18 & - & 17 & 23 & 40 & 40 \\
\hline Lee et al, $2016^{33}$ & Prospective & $70.85(7.70)$ & 809 & 76 & - & 885 & 233 & 885 & 885 \\
\hline Lee et al, $2016^{25}$ & Prospective & $70.4(6.13)$ & 139 & 9 & 28 & 61 & 59 & 120 & 148 \\
\hline Yousef and Alkhiary, $2017^{26}$ & Prospective & $48.9(8.29)$ & 188 & 0 & 60 & 60 & 68 & 128 & 188 \\
\hline Xiong et al, $2017^{27}$ & Prospective & $69.65(7.15)$ & 252 & 412 & 296 & 368 & - & 368 & 664 \\
\hline Rahimirad et al, $2017^{37}$ & Retrospective & $69.89(10.87)$ & 174 & $|4|$ & - & - & 315 & 315 & 315 \\
\hline Kumar et al, $2017^{21}$ & Retrospective & $71(10)$ & 93 & 88 & - & 181 & 181 & 181 & 181 \\
\hline Mohamed-Hussein et al, $2017^{34}$ & Retrospective & $58.1(16.95)$ & 107 & 41 & - & 74 & 74 & 148 & 148 \\
\hline Yao et al, $2017^{38}$ & Retrospective & $61(10)$ & 200 & 103 & - & - & 303 & 303 & 303 \\
\hline Farah et al, $2017^{28}$ & Prospective & $58.1(10.70)$ & 72 & 28 & 15 & 13 & 72 & 85 & 100 \\
\hline Acartürk et al, $2017^{35}$ & Retrospective & $66(13)$ & 636 & 430 & - & 993 & 73 & 1,066 & 1,066 \\
\hline
\end{tabular}

Note: Values are given as geometric mean \pm SD.

Abbreviation: NS, not specified.

higher than that in stable patients and healthy controls $(P<0.0005)$ (Figure 2). There were no significant differences between stable COPD patients and healthy controls when one-way ANOVA with Bonferroni post hoc test was used, but differences were found using an unpaired $t$-test $(P<0.0001)$.

Two observational prospective studies have assessed the NLR as an independent predictor of COPD exacerbation during the first year follow-up, although only one found statistically significant differences (OR 2.083, 95\% CI: 0.918-4.723, $P=0.079^{25}$ and OR $2.05,95 \%$ CI: $\left.1.03-4.06, P=0.041^{33}\right)$.

The accuracy of NLR data for detecting COPD exacerbation was described in seven articles (Table 4). ${ }^{9,10,23,24,26,34,35}$ The median cut-off value for a high NLR was 3.34 (range 1.5-3.35) with a sensitivity, specificity, and under the curve (AUC) being in the range 69\%-93\%, 59\%-90\%, and $0.58-0.89$, respectively. Three articles described the accuracy of NLR data for distinguishing between bacterial and nonbacterial exacerbation in patients admitted to the emergency room with a diagnosis of acute exacerbation of COPD. ${ }^{28,32,36}$ The median cut-off value for detecting bacterial infection in exacerbated patients was 7.30 (range 4.52-11.5) with a sensitivity, specificity, and AUC in the range 61\%-91\%, $46 \%-73.1 \%$, and $0.58-0.79$, respectively (Table 4).

\section{Correlation between NLR and clinical outcomes in COPD patients}

Six authors evaluated the correlation between NLR and $\mathrm{FEV}_{1} \cdot{ }^{24-26,30,33,34}$ In four articles, the data were analyzed using Pearson's correlation coefficient ${ }^{24-26,33}$ and in two using Spearman's rank correlation (Spearman's Rho) (Table 5). Five articles showed a significant negative correlation between the two parameters. Pooled data showed a median Pearson's correlation of -0.22 (range -0.17 to -0.28 ) and a median Spearman's correlation of -0.43 (range -0.38 to -0.49 ).

Three articles evaluated the relationship between the NLR values and GOLD stages, ${ }^{22,23,31}$ and a pooled analysis showed no significant differences in NLR values between GOLD stages (GOLD 1/2: 2.40 \pm 0.36 and GOLD 3/4: 2.22 \pm 0.36 ; $P=0.63)$. However, one study showed positive linear relationship between NLR and COPD severity in the stable group, whereas the results in patients exacerbated in stages 1 and 4 were similar (Table 6). ${ }^{23}$

The correlation between NLR and other clinical parameters was evaluated by two authors..$^{25,30}$ However, the heterogeneity in the statistical analysis precludes pooling the results. Furutate et $\mathrm{al}^{30}$ showed a significant positive correlation between NLR and mMRC or BODE index 
Table 2 Study quality assessment using the Newcastle-Ottawa scale

\begin{tabular}{|c|c|c|c|c|}
\hline Studies & Selection & Comparability & Outcome & Total stars \\
\hline \multicolumn{5}{|l|}{ Cohort studies } \\
\hline Sørensen et al, $2015^{29}$ & $\star \star \star \star$ & $\star \star$ & $\star \star \star$ & 9 \\
\hline Saltürk et al, $2015^{19}$ & $\star \star \star \star$ & $\star$ & $\star \star \star$ & 8 \\
\hline Duman et al, $2015^{20}$ & $\star \star \star \star$ & $\star \star$ & $\star \star \star$ & 9 \\
\hline Lee et al, $2016^{33}$ & $\star \star \star \star$ & $\star \star$ & $\star \star$ & 8 \\
\hline Kumar et al, $2017^{21}$ & $\star \star \star \star$ & $\star$ & $\star \star \star$ & 8 \\
\hline Studies & Selection & Comparability & Exposure & Total stars \\
\hline \multicolumn{5}{|l|}{ Cross-sectional studies } \\
\hline Tanriverdi et al, $2015^{36}$ & $\star \star \star$ & $\star$ & $\star \star \star$ & 7 \\
\hline Kurtipek et al, $2015^{9}$ & $\star \star \star \star$ & $\star \star$ & $\star \star \star$ & 9 \\
\hline Bilir et al, $2016^{23}$ & $\star \star \star \star \star$ & $\star \star$ & $\star \star \star$ & 10 \\
\hline Furutate et al, $2016^{30}$ & $\star \star \star \star$ & $\star \star$ & $\star \star \star$ & 9 \\
\hline Duyar, 2016 $6^{31}$ & $\star \star$ & - & $\star \star \star$ & 5 \\
\hline Acartürk et al, $2017^{35}$ & $\star \star \star \star$ & $\star$ & $\star \star \star$ & 8 \\
\hline Studies & Selection & Comparability & Exposure & Total stars \\
\hline \multicolumn{5}{|l|}{ Case-control studies } \\
\hline Günay et al, $2014^{22}$ & $\star \star \star \star$ & $\star$ & $\star \star \star$ & 8 \\
\hline Taylan et al, $2015^{10}$ & $\star \star \star \star$ & $\star \star$ & $\star \star$ & 8 \\
\hline In et al, $2016^{24}$ & $\star \star \star \star$ & $\star$ & $\star \star \star$ & 8 \\
\hline van de Geijn et al, $2016^{32}$ & $\star \star \star$ & $\star$ & $\star \star \star$ & 7 \\
\hline Lee et al, $2016^{25}$ & $\star \star \star \star$ & $\star \star$ & $\star \star \star$ & 9 \\
\hline Yousef and Alkhiary, $2017^{26}$ & $\star \star \star \star$ & $\star \star$ & $\star \star \star$ & 9 \\
\hline Xiong et al, $2017^{27}$ & $\star \star \star \star$ & $\star \star$ & $\star \star \star$ & 9 \\
\hline Rahimirad et al, $2017^{37}$ & $\star \star \star$ & $\star \star$ & $\star \star \star$ & 8 \\
\hline Mohamed-Hussein et al, $2017^{34}$ & $\star \star \star$ & - & $\star \star \star$ & 6 \\
\hline Yao et al, $2017^{38}$ & $\star \star \star$ & $\star$ & $\star \star \star$ & 7 \\
\hline Farah et al, $2017^{28}$ & $\star \star \star$ & $\star$ & $\star \star \star$ & 7 \\
\hline
\end{tabular}

Table 3 NLR value of healthy controls, and stable and exacerbated COPD patients

\begin{tabular}{|c|c|c|c|c|}
\hline \multirow[t]{2}{*}{ Author, year } & \multicolumn{4}{|c|}{ NLR, mean (SD) } \\
\hline & Control & Stable COPD & Exacerbated COPD & $P$-value \\
\hline Günay et al, $2014^{22}$ & I.7I (0.4I) & $2.59(1.05)$ & $4.28(2.38)$ & $<0.001$ \\
\hline Tanriverdi et al, $2015^{36}$ & - & - & $18.5(16.60)$ & - \\
\hline Sørensen et al, $2015^{29}$ & - & $3.08(0.76)$ & - & - \\
\hline Taylan et al, $2015^{10}$ & $1.7(0.90)$ & $3.1(2.50)$ & $7.1(5.40)$ & $<0.001$ \\
\hline Saltürk et al, $2015^{19}$ & - & $5.86(1.80)$ & $9.45(2.80)$ & - \\
\hline Duman et al, $2015^{20}$ & - & $5.18(1.39)$ & $6.12(1.73)$ & - \\
\hline Kurtipek et al, $2015^{9}$ & - & $2.75(\mathrm{I} . \mathrm{II})$ & $7.99(5.72)$ & 0.001 \\
\hline Bilir et al, $2016^{23}$ & $1.9(0.66)$ & $2.4 \mathrm{I}(2.90)$ & $4.22(2.5 I)$ & $<0.001$ \\
\hline Furutate et al, $2016^{30}$ & - & $2.56(0.23)$ & - & $<0.001$ \\
\hline In et al, $2016^{24}$ & $\mathrm{I} .68(0.4 \mathrm{I})$ & $2.67(1.13)$ & $5.78(3.14)$ & $<0.05$ \\
\hline Duyar, $2016^{31}$ & - & $2.14(0.40)$ & - & - \\
\hline van de Geijn et al, $2016^{32}$ & - & $3.08(1.5 \mathrm{I})$ & $5.89(4.92)$ & $<0.001$ \\
\hline Lee et al, $2016^{33}$ & - & $2.4(0.27)$ & - & - \\
\hline Lee et al, $2016^{25}$ & I.4 (0.50) & $2.4(0.70)$ & $12.4(10.60)$ & $<0.001$ \\
\hline Yousef and Alkhiary, $2017^{26}$ & $\mathrm{I} .45(0.2 \mathrm{I})$ & $2.36(0.55)$ & $4.44(\mathrm{I} .6 \mathrm{I})$ & $<0.001$ \\
\hline Xiong et al, $2017^{27}$ & $2.02(1.92)$ & $2.98(1.89)$ & - & - \\
\hline Rahimirad et al, $2017^{37}$ & - & - & $10.22(11.19)$ & - \\
\hline Kumar et al, $2017^{21}$ & - & - & $10(9)$ & - \\
\hline Mohamed-Hussein et al, $2017^{34}$ & - & $1.2(0.70)$ & $3.7(0.30)$ & $<0.05$ \\
\hline Yao et al, $2017^{38}$ & - & - & $7.92(8.79)$ & - \\
\hline Farah et al, $2017^{28}$ & $1.9(0.60)$ & $3.8(2.20)$ & $6.3(5.40)$ & $<0.001$ \\
\hline
\end{tabular}

Note: Values are given as geometric mean \pm SD.

Abbreviation: NLR, neutrophil-to-lymphocyte ratio. 


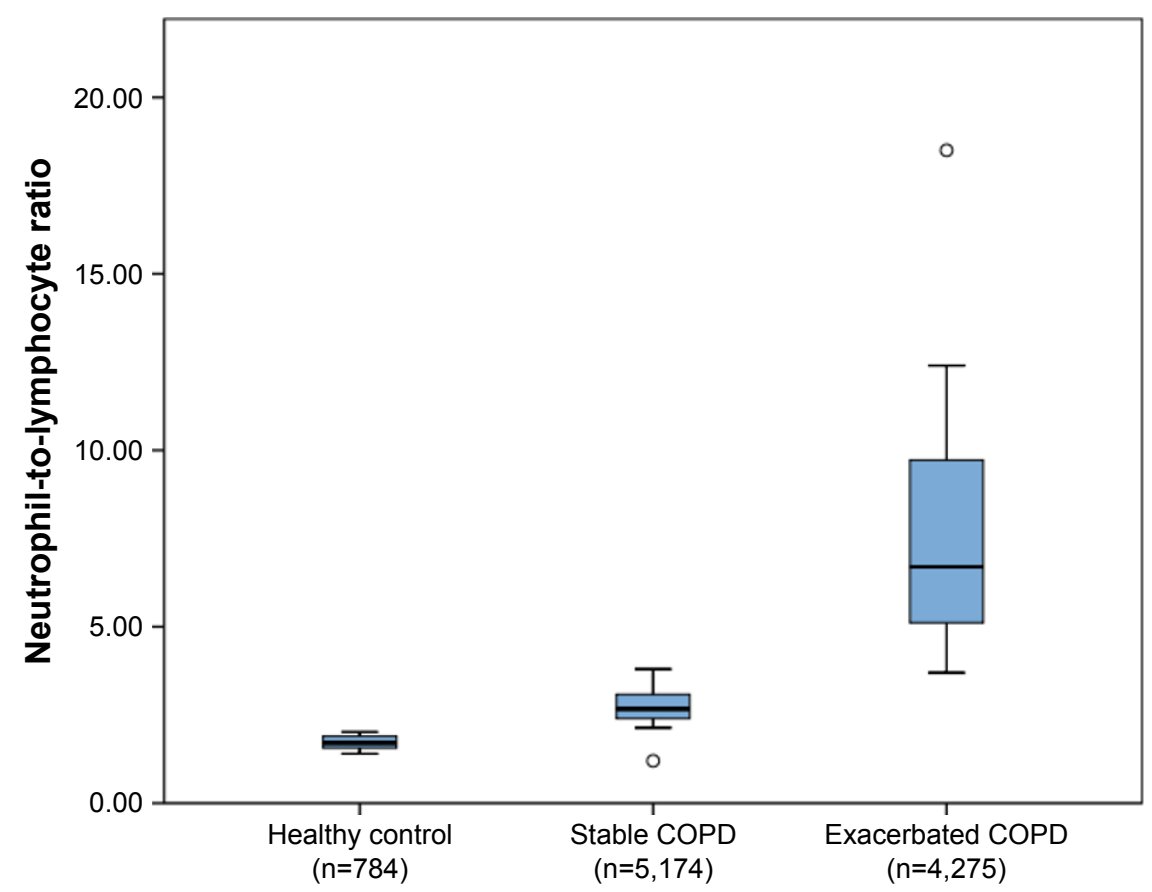

Figure 2 Neutrophil-to-lymphocyte ratio in healthy controls, and stable and exacerbated COPD patients. Note: Box plots represent median, interquartile range, and range with outliers plotted separately.

(Rho=0.403; $P<0.001$ and Rho=0.46; $P<0.001$, respectively). Likewise, Lee et $\mathrm{al}^{25}$ showed a significant positive correlation between these parameters $(r=0.39 ; P=0.01$ and $r=0.45 ; P=0.003$, respectively).

\section{NLR and other inflammatory biomarkers in COPD patients}

Data on the correlation between NLR and other inflammatory parameters were extracted from ten articles (Table 7). ${ }^{9,10,22-24,26,28,30,34,38}$ CRP was the most frequently evaluated parameter. ${ }^{9,10,22-24,26,28,30,38}$ The pooled data show that the median correlation between NLR and CRP values was Rho $=0.43$ (range $0.20-0.48$ ) in stable COPD patients.
In exacerbated COPD patients, four articles analyzed the data using Pearson's correlation coefficient ${ }^{9}, 10,26,38$ and two using Spearman's rank correlation (Spearman's Rho), ${ }^{22,23}$ showing a median of 0.46 (range $0.28-0.60$ ) and 0.59 (range $0.53-0.66$ ), respectively. In all articles, the correlation was statistically significant. Analyzing the comparative individual studies, a similar trend was observed in both CRP and NLR markers during the stable and exacerbation phases of COPD (CRP $7.39 \pm 8.15 \mathrm{mg} / \mathrm{dL}$ stable vs $26.49 \pm 24.32 \mathrm{mg} / \mathrm{dL}$ exacerbated; $P<0.001)$. The median cut-off value of CRP for detecting AECOPD was $2.56 \mathrm{mg} / \mathrm{dL}$ (range 1.17-3.35) with a sensitivity, specificity, and AUC in the range $68 \%-91 \%$, $52 \%-62 \%$, and $0.75-0.82$, respectively.

Table 4 Accuracy data of NLR for detecting COPD global and bacterial infection exacerbation

\begin{tabular}{|c|c|c|c|c|}
\hline Author, year & Cut-off & Sensitivity (\%) & Specificity (\%) & AUC (95\% CI) \\
\hline Kurtipek et al, $2015^{9, a}$ & 3.30 & 87 & 82 & 0.88 (NS) \\
\hline Tanrıverdi et al, $2015^{36, b}$ & 11.50 & 61 & 52 & $0.58(0.45-0.7 I)$ \\
\hline Taylan et al, $2015^{10, a}$ & 3.29 & 80.80 & 77.70 & $0.89(0.84-0.94)$ \\
\hline Bilir et al, $2016^{23, a}$ & 3.35 & 69 & 59 & $0.68(0.63-0.73)$ \\
\hline In et al, $2016^{24, a}$ & 3.34 & 78.70 & 73.20 & $0.86(0.79-0.93)$ \\
\hline van de Geijn et al, $2016^{32, b}$ & 4.52 & 91 & 46 & $0.75(0.60-0.91)$ \\
\hline Yousef and Alkhiary, $2017^{26, a}$ & 3.12 & 86.70 & 76.70 & $0.88(0.90-1.00)$ \\
\hline Mohamed-Hussein et al, $2017^{34, a}$ & 1.50 & 93 & 90 & $0.68(0.54-0.8 I)$ \\
\hline Farah et al, $2017^{28, b}$ & 7.30 & 76.80 & 73.10 & 0.79 (NS) \\
\hline Acartürk et al, $2017^{35, a}$ & 3.54 & 78 & 69 & - \\
\hline
\end{tabular}

Notes: ${ }^{a}$ NLR for detecting COPD global exacerbation; 'NLR for detecting COPD bacterial infection exacerbation.

Abbreviations: AUC, area under the curve; NLR, neutrophil-to-lymphocyte ratio; NS, not specified. 
Table 5 Correlation data between NLR and FEV,

\begin{tabular}{|c|c|c|}
\hline Author, year & $\begin{array}{l}\text { Correlation } \\
\text { coefficient }\end{array}$ & $P$-value \\
\hline Furutate et al, $2016^{30}$ & Rho $=-0.387$ & $<0.001$ \\
\hline In et al, $2016^{24}$ & $r=-0.288$ & 0.003 \\
\hline Lee et al, $2016^{33}$ & $r=-0.176$ & $<0.001$ \\
\hline Lee et al, $2016^{25}$ & $r=-0.285$ & 0.071 \\
\hline Yousef and Alkhiary, $2017^{26}$ & $r=-0.176$ & $<0.001$ \\
\hline Mohamed-Hussein et al, $2017^{34}$ & Rho $=-0.498$ & $<0.01$ \\
\hline
\end{tabular}

Abbreviations: $r$, Pearson's correlation coefficient; Rho, Spearman's rank correlation coefficient; NLR, neutrophil-to-lymphocyte ratio.

The second most studied parameter was ESR. The pooled data show that the median correlation between NLR and ESR values was $r=0.42$ (range $0.27-0.71)^{10,26}$ and Rho $=0.49$ (range $0.29-0.55)^{34}$ in exacerbated patients, and only one article showed a significant correlation between parameters in total COPD patients $(\mathrm{Rho}=0.26 ; P<0.001) .{ }^{24}$ Likewise, three articles showed a significant positive correlation between NLR and leukocytes. ${ }^{10,26,34}$ The pooled data show a median Pearson's correlation of $r=0.49$ (range 0.30-0.69). Only one article reported Spearman's Rho (Rho=0.33; $P<0.05),{ }^{34}$ and the correlation between NLR and leukocytes was evaluated only in exacerbated COPD patients.

Analyzing individual studies for which data were available,, ,10,19,20,22-24,26,28,32 although all markers showed significant differences in mean values between the stable and exacerbation phases, the difference was quantitatively greater in the NLR (3.57 \pm 1.54 stable vs $6.72 \pm 4.77$ exacerbated) than in the absolute values of neutrophils $(5.76 \pm 1.08 \times 103 / \mu \mathrm{L}$ stable vs $7.36 \pm 1.55 \times 103 / \mu \mathrm{L}$ exacerbated) or lymphocytes $(1.54 \pm 0.59 \times 103 / \mu \mathrm{L}$ stable vs $1.19 \pm 0.54 \times 103 / \mu \mathrm{L}$ exacerbated) assessed separately, with differences between their absolute values being $3.15,1.6$, and -0.35 , respectively.

Two studies ${ }^{19,20}$ analyzed the relationship between eosinophilia and the NLR in acute and stable phase patients. In both studies, the NLR was higher in patients with a lower percentage of eosinophils $(<2 \%)$ both in stable COPD (overall mean value, $6.99 \pm 1.25$ vs $3.99 \pm 0.71, P=0.001)$ and in AECOPD (11.33 \pm 2.11 vs $4.25 \pm 0.65, P=0.001)$.

\section{Prognostic significance of NLR in COPD patients}

Five articles found that the NLR represents an independent predictor of mortality in COPD patients (Table 8). ${ }^{19-21,27,37}$ Saltürk et $\mathrm{al}^{19}$ and Rahimirad et $\mathrm{al}^{37}$ conducted a multivariate analysis and found that high NLR values represent an independent predictor of in-hospital mortality during exacerbation, showing 2-3.5-fold more probability (OR 1.96, 95\% CI: $1.13-3.39 ; P=0.016$ and OR 3.586, 95\% CI: $1.69-7.60$; $P=0.001$, respectively) with a median NLR cut-off value of 10 (range 4-16). On the other hand, Duman et al, ${ }^{20}$ Xiong et $a l,{ }^{27}$ and Kumar et $\mathrm{al}^{21}$ found that the NLR is an independent predictor of early (first 90 days) and late (within 6 and 24 months) mortality during the follow-up after exacerbation. According to Duman et al, ${ }^{20}$ there was an almost twofold (OR 1.79, 95\% CI: 1.37-2.34; $P=0.001$ ) higher probability of mortality within 6 months after exacerbation with an NLR cut-off value of 7 , while Xiong et $\mathrm{al}^{27}$ showed that there was an almost fourfold (OR 3.95, 95\% CI: 2.54-6.38; $P<0.001$ ) higher probability of mortality within 24 months after exacerbation with an NLR cut-off value of 3.3.

\section{Discussion}

COPD is characterized by an increase in pulmonary and systemic inflammatory responses ${ }^{39}$ that are maintained after smoking cessation and could progressively increase over time. ${ }^{40}$ Different studies have shown that lung inflammation induced by COPD is mediated by innate and adaptive immune system deprivation. ${ }^{41,42}$

Changes in the innate immune system in COPD patients are related to injury of the alveolar epithelium, a decrease in phagocytosis mediated by macrophages, a reduction in dendritic cells in airways, and an increase in neutrophil migration into the airways that is not accompanied by correct bacterial clearance. This neutrophil migration stimulates cytokine production and subsequent destruction of lung tissue, ${ }^{40,43-45}$ which leads to changes in the microbiome of patients with COPD that seem to be related to the perpetuation of the inflammatory response in the airway despite the cessation of smoking. ${ }^{46}$

Table 6 NLR during stable and exacerbation periods according to GOLD stage

\begin{tabular}{|c|c|c|c|c|c|c|}
\hline Author, year & Group & GOLD I & GOLD 2 & GOLD 3 & GOLD 4 & $P$-value \\
\hline \multirow[t]{2}{*}{ Günay et al, $2014^{22}$} & Stable & $2.44(1.19)$ & $2.90(2.00)$ & $2.46(1.4 I)$ & $3.16(4.87)$ & 0.254 \\
\hline & Exacerbation & 2.29 (4.39) & $4.28(3.5 \mathrm{I})$ & $4.35(4.26)$ & $6.15(5.38)$ & 0.178 \\
\hline \multirow[t]{2}{*}{ Bilir et al, $2016^{23}$} & Stable & $1.64(1.60)$ & $2.33(2.09)$ & $2.60(3.58)$ & $2.66(3.86)$ & $<0.001$ \\
\hline & Exacerbation & $6.19(2.94)$ & $4.18(4.48)$ & $3.47(3.53)$ & $6.29(6.38)$ & 0.028 \\
\hline Duyar, 201631 & Stable & \multicolumn{2}{|c|}{ I.8I (0.33) } & \multicolumn{2}{|c|}{$2.57(0.34)$} & 0.091 \\
\hline
\end{tabular}

Note: Values are given as geometric mean \pm SD. 
Table 7 Correlation between NLR and other inflammatory parameters in COPD patients

\begin{tabular}{|c|c|c|c|c|}
\hline \multirow[t]{2}{*}{ Correlation } & \multirow[t]{2}{*}{ Authorlyear } & \multicolumn{3}{|l|}{ COPD } \\
\hline & & Stable & Exacerbated & Total \\
\hline \multirow[t]{9}{*}{ NLR/CRP } & Günay et al, $2014^{22}$ & Rho $=0.485, P<0.001$ & Rho $=0.665, P<0.00 \mathrm{I}$ & - \\
\hline & Taylan et al, $2015^{10}$ & - & $r=0.415, P<0.001$ & - \\
\hline & Kurtipek et al, $2015^{9}$ & - & $r=0.512, P<0.00 I$ & - \\
\hline & Bilir et al, $2016^{23}$ & Rho $=0.436, P<0.001$ & Rho $=0.534, P<0.001$ & - \\
\hline & Furutate et al, $2016^{30}$ & Rho $=0.209, P=0.015$ & - & - \\
\hline & In et al, $2016^{24}$ & - & - & $r=0.64 \mathrm{I}, P<0.00 \mathrm{I}$ \\
\hline & Yousef and Alkhiary, $2017^{26}$ & - & $r=0.609, P<0.000$ & - \\
\hline & Yao et al, $2017^{38}$ & - & $r=0.28 I, P<0.001$ & - \\
\hline & Farah et al, $2017^{28}$ & - & - & $r=0.556, P<0.000$ \\
\hline \multirow[t]{4}{*}{ NLR/ESR } & Taylan et al, $2015^{10}$ & - & $r=0.275, P=0.035$ & - \\
\hline & In et al, $2016^{24}$ & - & - & $r=0.276, P=0.005$ \\
\hline & Yousef and Alkhiary, $2017^{26}$ & - & $r=0.714, P<0.000$ & - \\
\hline & Mohamed-Hussein et al, $2017^{34}$ & - & Rho $=0.558, P<0.01$ & - \\
\hline \multirow[t]{3}{*}{ NLR/WBC } & Taylan et al, $2015^{10}$ & - & $r=0.304, P=0.002$ & - \\
\hline & Yousef and Alkhiary, $2017^{26}$ & - & $r=0.694, P<0.000$ & - \\
\hline & Mohamed-Hussein et al, $2017^{34}$ & - & Rho $=0.330, P<0.01$ & - \\
\hline
\end{tabular}

Abbreviations: CRP, C-reactive protein; ESR, erythrocyte sedimentation rate; NLR, neutrophil-to-lymphocyte ratio; Rho, Spearman's rank correlation coefficient; $r$, Pearson's correlation coefficient; WBC, white blood cell.

Changes in the adaptive immune system are due to an increase in $\mathrm{CD} 8{ }^{+} \mathrm{T}$ lymphocytes within the airway, ${ }^{42}$ which has been related to the production of larger amounts of cytotoxic perforins, granzyme B, and macrophage elastase (MMP-12), leading to tissue damage..$^{47}$ On the other hand, some studies have found that $\mathrm{CD} 4^{+} \mathrm{T}$ lymphocytes participate in the amplification of the adaptive immune response. ${ }^{48}$ In addition, they seem to play a role in the development of autoimmunity; ${ }^{49}$ however, the clinical role of these data remains to be elucidated.

Several studies have suggested that patients with COPD present elevated serum inflammatory markers. It has been estimated that $\sim 70 \%$ of patients with COPD have at least one elevated serum inflammatory parameter. ${ }^{49}$ Some data have shown that the persistent elevation of inflammatory markers is related to the progression of the disease,${ }^{50}$ clinical and functional parameters, ${ }^{51}$ and the development of comorbidities. ${ }^{40}$ The most studied serum inflammatory markers are CRP, IL-6, and TNF- $\alpha .{ }^{50}$ However, their use in routine clinical practice has limitations, while NLR is a rapid, easy, and cost-effective method derived from routine complete blood count tests. The NLR has been reported to be a useful indicator of clinical outcome and severity in malignant and inflammatory diseases. ${ }^{51-54}$

In the present study, the NLR showed a positive and significant correlation with other traditional inflammatory markers such as CRP, leukocytes, and ESR. Analyzing the comparative individual studies, a similar trend was observed in both CRP and NLR markers during the stable and exacerbation phases of COPD. Therefore, the data seem to indicate that both are equally effective in the detection of AECOPD. However, NLR is easy to calculate from a routine complete blood count and is cheaper than serum CRP-level measurement. On the other hand, the difference is quantitatively greater in the NLR compared to absolute values of neutrophils and lymphocytes, which is expected, since the NLR includes both biomarkers. This analysis shows the potential usefulness of NLR as an inflammatory marker in patients with COPD and indicates the possibility of using the NLR as a useful marker in routine clinical

Table 8 Predictive value of NLR in COPD patients' mortality based on multivariate analysis

\begin{tabular}{|c|c|c|c|c|c|}
\hline Author, year & Cut-off & Odds ratio & $95 \% \mathrm{Cl}$ & $P$-value & Event \\
\hline Saltürk et al, $2015^{19}$ & $N L R \geq 16$ & 1.96 & $1.13-3.39$ & 0.016 & In-hospital mortality (respiratory failure) \\
\hline Duman et al, $2015^{20}$ & $N L R \geq 7$ & 1.79 & I.37-2.34 & 0.001 & Late mortality (within 6 months) \\
\hline Xiong et al, $2017^{27}$ & $N L R \geq 3.3$ & 3.95 & $2.54-6.38$ & $<0.001$ & Late mortality (within 24 months) \\
\hline Rahimirad et al, $2017^{37}$ & $N L R \geq 4$ & 3.586 & $1.69-7.60$ & 0.001 & In-hospital mortality \\
\hline Kumar et al, $2017^{21}$ & - & 0.95 & $0.84-1.08$ & 0.46 & Early mortality (at 90 days after hospital admission) \\
\hline
\end{tabular}

Abbreviation: NLR, neutrophil-to-lymphocyte ratio. 
practice, although more validation studies are required in this regard.

The pooling of data in this systematic review demonstrated that the NLR value was significantly elevated in stable COPD patients compared with healthy subjects, which suggests that systemic inflammation is persistent in this population. This observation is consistent with other published data that showed elevation of inflammatory markers such as IL-6 and CRP in patients with stable COPD compared with healthy controls. ${ }^{55-57}$

It was also shown that exacerbated COPD patients had significantly higher NLR values compared with stable COPD patients. In addition, it was observed that the NLR decreased in patients with exacerbated COPD after recovery of the exacerbation. ${ }^{10,19,21}$ These findings are consistent with other studies in which the same behavior of other inflammatory markers was observed, along with a greater inflammatory response during exacerbation of COPD. ${ }^{58,59}$ Taken together, these data suggest that the NLR is a marker that could be used to evaluate the inflammatory status of patients with COPD and predict the remission of the inflammatory process during exacerbations.

In the present systematic review, only one out of two single studies found that elevation of the NLR is an independent predictor of acute exacerbation in patients with COPD, with a twofold increase in the likelihood of exacerbation in patients with a high NLR in the stable phase. A previous prospective study demonstrated that the single best predictor of future exacerbations, across all GOLD stages, was a treated exacerbation in the year before study entry (OR 4.30, 95\% CI: $3.58-5.17 ; P<0.001) .{ }^{60}$ Other studies have also shown a predictive value of other inflammatory markers for acute exacerbation in COPD patients. ${ }^{58,61}$ Hence, the discordant findings of the NLR in the present review do not support the value of this marker as a predictor of future exacerbations. However, the NLR seems to be a good marker for detecting an acute exacerbation in COPD patients. The pooled data indicate that a cut-off value of 3.34 would allow the diagnosis of acute exacerbation with a median AUC of 0.86 , sensitivity of $80 \%$, and specificity of $86 \%$. Similarly, the pooled data suggest a median cut-off value of 7.30 for detecting infectious exacerbation of COPD patients with a median AUC of 0.75 , but with a wide range of cut-off values and rather low sensitivity (76.8\%) and specificity (52\%). The possibility that the NLR could predict bacterial exacerbation appears more interesting, in view of its clinical implications. Although the results shown here do not support this hypothesis, future studies are required to validate this information.
In our review, the NLR was higher in patients with a lower percentage of eosinophils $(<2 \%)$ both in stable COPD and in AECOPD, and it should be noted that these patients presented greater therapeutic failure after corticosteroid treatment for the exacerbation. These findings agree with other studies that show a negative correlation between the eosinophil count and bacterial isolates in the sputum of patients with stable COPD.$^{62}$ The percentage of blood eosinophils is also inversely correlated to the presence of bacterial infection in AECOPD. ${ }^{62}$ Hence, the combination of both markers (NLR and eosinophilia) could identify a therapeutic phenotype (the one that requires antibiotic and/or the one that requires systemic corticosteroids). Therefore, NRL could be used to monitor the exacerbation and to support therapeutic decision making.

On the other hand, no statistically significant differences were found in the NLR when patients were stratified using the GOLD airflow obstruction classification. However, one study showed a positive linear relationship between NLR and COPD severity in the stable group. ${ }^{23}$ The data regarding the association of inflammatory markers with GOLD classification are contradictory. In this regard, De Moraes et al ${ }^{55}$ found no direct association between IL-6 and IL-8 and the severity of COPD in ex-smokers. Nevertheless, Mathanraj et $\mathrm{al}^{63}$ and Torres-Ramos et $\mathrm{al}{ }^{56}$ reported a significant increase in TNF- $\alpha$ and CRP, respectively, according to GOLD stage. The findings in the different studies show the heterogeneity of the cohorts studied and the potential impact of comorbidities associated with COPD on systemic inflammatory markers. In addition, a high percentage of patients in GOLD stage II (about 22\% according to the ECLIPSE study) ${ }^{60}$ also have frequent exacerbations, which are related to an increased and persistent inflammatory status in the stable stage.

The relationship between inflammatory markers and clinical/functional parameters in COPD patients was described in some articles. A positive correlation between IL-6 and a rapid decline in FEV ${ }_{1}$ has been demonstrated previously. ${ }^{51,59}$ Other authors reported a significant correlation between IL-6, CRP, and BODE index. ${ }^{64,65}$ These data suggest that the inflammatory status of COPD patients is associated with disease progression, and worsening dyspnea and exercise tolerance..$^{55}$ In the present review, some authors found a moderate correlation between NLR and $\mathrm{FEV}_{1}, \mathrm{mMRC}$, and BODE index. These findings suggest that NLR could be used as a clinical performance marker in COPD patients..$^{25,30}$

The prognostic value of different inflammatory markers in COPD patients has previously been reported by other authors. 
In a cross-sectional prospective study, Shafiek et al ${ }^{66}$ found that high levels of IL-6 predict in-hospital mortality. Similarly, a recent meta-analysis found that a high baseline level of CRP is significantly associated with higher late mortality in COPD patients. ${ }^{67}$ Other inflammatory markers such as IL-1 $\beta$ and fibronectin have also been described to be associated with mortality of COPD. ${ }^{68}$ In the present study, we found that the NLR is an independent predictor of in-hospital mortality, with 2-3.5-fold higher probability of mortality with a median NLR cut-off value of 10 . In addition, the NLR seems to be an independent predictor of late mortality, with a high NLR value being associated with two- to four fold higher probability of death after exacerbation. All-cause mortality analysis is the method most usually performed in the studies, and the influence of other systemic diseases (such as lung cancer) on the NLR may introduce a certain bias. However, in favor of the NLR as an AECOPD biomarker, Rahimirad et $\mathrm{al}^{37}$ showed a statistically significant relationship between the ratio and the in-hospital mortality due to respiratory causes.

Regarding the potential effect of the patient's treatment on the NLR, most studies in this review excluded patients with a history of antibiotic treatment and the use of systemic steroids in at least the two preceding months. Hence, treatment with steroids was started at the time of AECOPD diagnosis; it was thus able to influence the subsequent neutrophil and lymphocyte counts, but not the baseline measurement. Dividing patients into two groups according to systemic glucocorticoid use at baseline, Sørensen et al ${ }^{29}$ concluded that treatment with systemic glucocorticoids has a significant impact on the ability of inflammatory biomarkers to predict all-cause mortality, with higher mortality in the group not undergoing this treatment. The use of inhaled corticosteroids to treat COPD patients is not recorded in the studies, and so the potential effect of this therapy on the NLR is unknown.

\section{Limitations}

There are several limitations in this systematic review. First, most studies included were retrospective, with the possibility of selection bias. Second, most studies included had a small number of patients. Furthermore, the heterogeneity in the methodology and the primary outcomes between studies limited the gathering of some clinical parameters evaluated. No meta-analysis was possible due to the heterogeneity and the impossibility of extracting the necessary data.

\section{Conclusion}

In conclusion, this is the most comprehensive systematic review to date to show that the NLR is higher in stable COPD patients than healthy controls, and that the NLR is also higher in exacerbated compared with stable COPD patients. The NLR is a good marker for detecting acute exacerbation in COPD patients. This systematic review proposes a cut-off value of 3.34, which achieves an acceptable degree of accuracy. There was no evidence of a relationship between NLR and GOLD airflow obstruction classification. However, we found that there was a significant correlation between the NLR and clinical/functional parameters $\left(\mathrm{FEV}_{1}, \mathrm{mMRC}\right.$, and BODE index) in COPD patients, which suggests that a high NLR could be associated with a worsening of dyspnea, clinical performance, and degree of bronchial obstruction. Besides, we found that the NLR may provide an added value to predict the risk of in-hospital and late mortality in COPD patients. Further prospective studies to address confounders with larger sample sizes and including different disease stages are needed to better identify the clinical value of the NLR.

\section{Acknowledgments}

The publication of this systematic review was supported by a grant from the Instituto de Salud Carlos III (Grant FISPI16/00193, co-funded by European Regional Development Fund [ERDF], a way to build Europe) to Salud Santos. The authors received no compensation related to the development of the manuscript.

\section{Author contributions}

All authors contributed toward data acquisition, analysis and interpretation of results, drafting and critically revising the paper, gave final approval of the version to be published, and agree to be accountable for all aspects of the work.

\section{Disclosure}

The authors report no conflicts of interest in this work.

\section{References}

1. Vogelmeier CF, Criner GJ, Martinez FJ, et al. Global strategy for the diagnosis, management, and prevention of chronic obstructive lung disease 2017 report. GOLD executive summary. Am J Respir Crit Care Med. 2017;195(5):557-582.

2. Lozano R, Naghavi M, Foreman K, et al. Global and regional mortality from 235 causes of death for 20 age groups in 1990 and 2010: a systematic analysis for the Global Burden of Disease Study 2010. Lancet. 2012; 380(9859):2095-2128.

3. Mathers CD, Loncar D. Projections of global mortality and burden of disease from 2002 to 2030. PLoS Med. 2006;3(11):e442.

4. Macnee W. Pathogenesis of chronic obstructive pulmonary disease. Proc Am Thorac Soc. 2005;2(4):258-266.

5. Walter RE, Wilk JB, Larson MG, et al. Systemic inflammation and COPD: the Framingham Heart Study. Chest. 2008;133(1):19-25.

6. Zhou X, Li Q, Zhou X. Exacerbation of Chronic Obstructive Pulmonary Disease. Cell Biochem Biophys. 2015;73(2):349-355. 
7. Groenewegen KH, Postma DS, Hop WC, et al. Increased systemic inflammation is a risk factor for COPD exacerbations. Chest. 2008; 133(2):350-357.

8. Sethi S, Murphy TF. Infection in the pathogenesis and course of chronic obstructive pulmonary disease. N Engl J Med. 2008;359(22): 2355-2365.

9. Kurtipek E, Bekci TT, Kesli R, Sami SS, Terzi Y. The role of neutrophillymphocyte ratio and platelet-lymphocyte ratio in exacerbation of chronic obstructive pulmonary disease. J Pak Med Assoc. 2015;65(12): 1283-1287.

10. Taylan M, Demir M, Kaya H, et al. Alterations of the neutrophillymphocyte ratio during the period of stable and acute exacerbation of chronic obstructive pulmonary disease patients. Clin Respir J. Epub 2015 Aug 6.

11. Cedrés S, Torrejon D, Martínez A, et al. Neutrophil to lymphocyte ratio (NLR) as an indicator of poor prognosis in stage IV non-small cell lung cancer. Clin Transl Oncol. 2012;14(11):864-869.

12. Walsh SR, Cook EJ, Goulder F, Justin TA, Keeling NJ. Neutrophillymphocyte ratio as a prognostic factor in colorectal cancer. J Surg Oncol. 2005;91(3):181-184.

13. Núñez J, Núñez E, Bodí V, et al. Usefulness of the neutrophil to lymphocyte ratio in predicting long-term mortality in ST segment elevation myocardial infarction. Am J Cardiol. 2008;101(6):747-752.

14. Turkmen K, Erdur FM, Ozcicek F, et al. Platelet-to-lymphocyte ratio better predicts inflammation than neutrophil-to-lymphocyte ratio in end-stage renal disease patients. Hemodial Int. 2013;17(3):391-396.

15. Moher D, Liberati A, Tetzlaff J, Altman DG; PRISMA Group. Preferred reporting items for systematic reviews and meta-analyses: the PRISMA statement. Ann Intern Med. 2009;151(4):264-269.

16. Wells GA, Shea B, O'Connell D. The Newcastle-Ottawa Scale (NOS) for assessing the quality of nonrandomized studies in meta-analyses. Available from: www.ohri.ca/programs/clinical_epidemiology/oxford.asp. Accessed January 10, 2018.

17. Viswanathan M, Patnode CD, Berkman ND, et al. Recommendations for assessing the risk of bias in systematic reviews of health-care interventions. J Clin Epidemiol. 2018;97:26-34.

18. Hozo SP, Djulbegovic B, Hozo I. Estimating the mean and variance from the median, range, and the size of a sample. BMC Med Res Methodol. 2005;5(1):13.

19. Saltürk C, Karakurt Z, Adiguzel N, et al. Does eosinophilic COPD exacerbation have a better patient outcome than non-eosinophilic in the intensive care unit? Int J Chron Obstruct Pulmon Dis. 2015;10: 1837-1846.

20. Duman D, Aksoy E, Agca MC, et al. The utility of inflammatory markers to predict readmissions and mortality in COPD cases with or without eosinophilia. Int J Chron Obstruct Pulmon Dis. 2015;10:2469-2478.

21. Kumar P, Law S, Sriram KB. Evaluation of platelet lymphocyte ratio and 90-day mortality in patients with acute exacerbation of chronic obstructive pulmonary disease. J Thorac Dis. 2017;9(6):1509-1516.

22. Günay E, Sarınç Ulaşlı S, Akar O, et al. Neutrophil-to-lymphocyte ratio in chronic obstructive pulmonary disease: a retrospective study. Inflammation. 2014;37(2):374-380.

23. Bilir B, Altıntaş N, Aydın M. The Predictive Role of Neutrophil to Lymphocyte ratio in Chronic Obstructive Pulmonary Disease. Eur $J$ Gen Med. 2016;13(2):105-110.

24. In E, Kuluöztürk M, Öner Ö, Deveci F. The Importance of Neutrophilto-Lymphocyte Ratio in Chronic Obstructive Pulmonary Disease. Turk Thorac J. 2016;17(2):41-46.

25. Lee SJ, Lee HR, Lee TW, et al. Usefulness of neutrophil to lymphocyte ratio in patients with chronic obstructive pulmonary disease: a prospective observational study. Korean J Intern Med. 2016;31(5):891-898.

26. Yousef AM, Alkhiary W. Role of neutrophil to lymphocyte ratio in prediction of acute exacerbation of chronic obstructive pulmonary disease. Egypt J Chest Dis Tuberc. 2017;66(1):43-48.

27. Xiong W, Xu M, Zhao Y, Wu X, Pudasaini B, Liu JM. Can we predict the prognosis of COPD with a routine blood test? Int J Chron Obstruct Pulmon Dis. 2017;12:615-625.
28. Farah R, Ibrahim R, Nassar M, Najib D, Zivony Y, Eshel E. The neutrophil/lymphocyte ratio is a better addition to C-reactive protein than CD64 index as a marker for infection in COPD. Panminerva Med. 2017;59(3):203-209.

29. Sørensen AK, Holmgaard DB, Mygind LH, Johansen J, Pedersen C. Neutrophil-to-lymphocyte ratio, calprotectin and YKL-40 in patients with chronic obstructive pulmonary disease: correlations and 5-year mortality - a cohort study. J Inflamm. 2015;12(1):20.

30. Furutate R, Ishii T, Motegi T, et al. The neutrophil to lymphocyte ratio is related to disease severity and exacerbation in patients with chronic obstructive pulmonary disease. Intern Med. 2016;55(3):223-229.

31. Duyar SS. Platelet to Lymphocyte Ratio as a Novel Prognostic Marker in Male Patients with Chronic Obstructive Pulmonary Disease. Int $J$ Respir Pulm Med. 2016;3(1):043.

32. van de Geijn GM, Denker S, Meuleman-van Waning V, et al. Evaluation of new laboratory tests to discriminate bacterial from nonbacterial chronic obstructive pulmonary disease exacerbations. Int $J$ Lab Hematol. 2016;38(6):616-628.

33. Lee H, Um SJ, Kim YS, et al. Association of the neutrophil-to-lymphocyte ratio with lung function and exacerbations in patients with chronic obstructive pulmonary disease. PLoS One. 2016;11(6):e0156511.

34. Mohamed-Hussein A, Aly SS, Asmaa M, Zahran AM. Neutrophil CD64 and neutrophil/lymphocyte ratio as predictors of hospital outcome in acute exacerbation COPD. IJASRM. 2017;2:7-17.

35. Acartürk Tunçay E, Karakurt Z, Aksoy E, et al. Eosinophilic and noneosinophilic COPD patients with chronic respiratory failure: neutrophilto-lymphocyte ratio as an exacerbation marker. Int J Chron Obstruct Pulmon Dis. 2017:12:3361-3370.

36. Tanrıverdi H, Örnek T, Erboy F, et al. Comparison of diagnostic values of procalcitonin, C-reactive protein and blood neutrophil/lymphocyte ratio levels in predicting bacterial infection in hospitalized patients with acute exacerbations of COPD. Wien Klin Wochenschr. 2015; 127(19-20):756-763.

37. Rahimirad S, Ghaffary MR, Rahimirad MH, Rashidi F. Association between admission neutrophil to lymphocyte ratio and outcomes in patients with acute exacerbation of chronic obstructive pulmonary disease. Tuberk Toraks. 2017;65(1):25-31.

38. Yao C, Liu X, Tang Z. Prognostic role of neutrophil-lymphocyte ratio and platelet-lymphocyte ratio for hospital mortality in patients with AECOPD. Int J Chron Obstruct Pulmon Dis. 2017;12:2285-2290.

39. Angelis N, Porpodis K, Zarogoulidis P, et al. Airway inflammation in chronic obstructive pulmonary disease. J Thorac Dis. 2014;6(Suppl 1): S167-S172.

40. King PT. Inflammation in chronic obstructive pulmonary disease and its role in cardiovascular disease and lung cancer. Clin Transl Med. 2015;4(1):68.

41. Shaykhiev R, Crystal RG. Innate immunity and chronic obstructive pulmonary disease: a mini-review. Gerontology. 2013;59(6):481-489.

42. Nurwidya F, Damayanti T, Yunus F. The Role of Innate and Adaptive Immune Cells in the Immunopathogenesis of Chronic Obstructive Pulmonary Disease. Tuberc Respir Dis. 2016;79(1):5-13.

43. Vlahos R, Bozinovski S. Role of alveolar macrophages in chronic obstructive pulmonary disease. Front Immunol. 2014;5:435.

44. Givi ME, Redegeld FA, Folkerts G, Mortaz E. Dendritic cells in pathogenesis of COPD. Curr Pharm Des. 2012;18(16):2329-2335.

45. Hoenderdos K, Condliffe A. The neutrophil in chronic obstructive pulmonary disease. Am J Respir Cell Mol Biol. 2013;48(5):531-539.

46. Sze MA, Dimitriu PA, Hayashi S, et al. The lung tissue microbiome in chronic obstructive pulmonary disease. Am J Respir Crit Care Med. 2012;185(10):1073-1080.

47. Maeno T, Houghton AM, Quintero PA, Grumelli S, Owen CA, Shapiro SD. CD8+ T Cells are required for inflammation and destruction in cigarette smoke-induced emphysema in mice. J Immunol. 2007;178(12):8090-8096.

48. Ju J. An Increased Proportion of Apoptosis in $\mathrm{CD}^{+} \mathrm{T}$ Lymphocytes Isolated from the Peripheral Blood in Patients with Stable Chronic Obstructive Pulmonary Disease. Tuberc Respir Dis. 2018;81(2):132-137. 
49. Oh JY, Sin DD. Lung inflammation in COPD: why does it matter? F1000 Med Rep. 2012;4:23.

50. Su B, Liu T, Fan H, et al. Inflammatory Markers and the Risk of Chronic Obstructive Pulmonary Disease: A Systematic Review and Meta-Analysis. PLoS One. 2016;11(4):e0150586.

51. Donaldson GC, Seemungal TA, Patel IS, et al. Airway and systemic inflammation and decline in lung function in patients with COPD. Chest. 2005;128(4):1995-2004.

52. Cataudella E, Giraffa CM, Di Marca S, et al. Neutrophil-To-Lymphocyte Ratio: An Emerging Marker Predicting Prognosis in Elderly Adults with Community-Acquired Pneumonia. J Am Geriatr Soc. 2017;65(8): 1796-1801.

53. Isaac V, Wu CY, Huang CT, Baune BT, Tseng CL, Mclachlan CS. Elevated neutrophil to lymphocyte ratio predicts mortality in medical inpatients with multiple chronic conditions. Medicine. 2016;95(23): e3832.

54. Yu Y, Qian L, Cui J. Value of neutrophil-to-lymphocyte ratio for predicting lung cancer prognosis: a meta-analysis of 7,219 patients. Mol Clin Oncol. 2017;7(3):498-506.

55. de Moraes MR, da Costa AC, Corrêa KS, Junqueira-Kipnis AP, Rabahi MF. Interleukin-6 and interleukin- 8 blood levels' poor association with the severity and clinical profile of ex-smokers with COPD. Int J Chron Obstruct Pulmon Dis. 2014;9:735-743.

56. Torres-Ramos YD, García-Guillen ML, Olivares-Corichi IM, Hicks JJ. Correlation of Plasma Protein Carbonyls and C-Reactive Protein with GOLD Stage Progression in COPD Patients. Open Respir Med J. 2009; 3(1):61-66.

57. Agustí A, Edwards LD, Rennard SI, et al. Persistent systemic inflammation is associated with poor clinical outcomes in COPD: a novel phenotype. PLoS One. 2012;7(5):e37483.

58. Gallego M, Pomares X, Capilla S, et al. C-reactive protein in outpatients with acute exacerbation of COPD: its relationship with microbial etiology and severity. Int J Chron Obstruct Pulmon Dis. 2016;11: 2633-2640.
59. Emami Ardestani M, Zaerin O. Role of Serum Interleukin 6, Albumin and C-Reactive Protein in COPD Patients. Tanaffos. 2015;14(2): 134-140.

60. Hurst JR, Vestbo J, Anzueto A. Evaluation of COPD Longitudinally to Identify Predictive Surrogate Endpoints (ECLIPSE) Investigators. Susceptibility to exacerbation in chronic obstructive pulmonary disease. N Engl J Med. 2010;363(12):1128-1138.

61. Koutsokera A, Kostikas K, Nicod LP, Fitting JW. Pulmonary biomarkers in COPD exacerbations: a systematic review. Respir Res. 2013; 14(1): 111

62. Kolsum U, Donaldson GC, Singh R, et al. Blood and sputum eosinophils in COPD; relationship with bacterial load. Respir Res. 2017; 18(1):88.

63. Mathanraj S, Vysak K, Yuvarajan S. Correlation of serum TNF alpha level with severity of chronic obstructive pulmonary disease. Int $J$ Res Med Sci. 2017;5(8):3309-3316.

64. Meshram PL, Shinde SN, Ramraje NN, Hegde RR. Study of inflammatory markers and BODE index in chronic obstructive pulmonary disease. Lung India. 2018;35(1):37-40.

65. Garcia-Rio F, Miravitlles M, Soriano JB, et al. Systemic inflammation in chronic obstructive pulmonary disease: a population-based study. Respir Res. 2010;11(1):63.

66. Shafiek H. Outcome Predictors of Severe Acute Exacerbation of Chronic Obstructive Pulmonary Disease: Role of Inflammatory Biomarkers. Int J Respir Pulm Med. 2016;3(2):047.

67. Leuzzi G, Galeone C, Taverna F, Suatoni P, Morelli D, Pastorino U. C-reactive protein level predicts mortality in COPD: a systematic review and meta-analysis. Eur Respir Rev. 2017;26(143):160070.

68. Kelly E, Owen CA, Pinto-Plata V, Celli BR. The role of systemic inflammatory biomarkers to predict mortality in chronic obstructive pulmonary disease. Expert Rev Respir Med. 2013;7(1):57-64.
International Journal of COPD

\section{Publish your work in this journal}

The International Journal of COPD is an international, peer-reviewed journal of therapeutics and pharmacology focusing on concise rapid reporting of clinical studies and reviews in COPD. Special focus is given to the pathophysiological processes underlying the disease, intervention programs, patient focused education, and self management protocols.

\section{Dovepress}

This journal is indexed on PubMed Central, MedLine and CAS. The manuscript management system is completely online and includes a very quick and fair peer-review system, which is all easy to use. Visit http://www.dovepress.com/testimonials.php to read real quotes from published authors. 